\title{
1 Agency plans are inadequate to conserve US endangered species under climate change
}

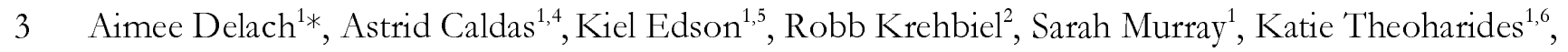

4 Lauren Vorhees ${ }^{1,7}$, Jacob W. Malcom³, Mark Salvo ${ }^{1}$ and Jennifer R. B. Miller ${ }^{3}$

6 Affiliations:

$7 \quad{ }^{1}$ Landscape Conservation, Defenders of Wildlife, $113017^{\text {th }}$ Street NW, Washington, DC 20036

$8 \quad{ }^{2}$ Field Conservation, Defenders of Wildlife, 1402 Third Ave, Suite \#930, Seattle, WA 98101

$9{ }^{3}$ Center for Conservation Innovation, Defenders of Wildlife, $113017^{\text {th }}$ Street NW, Washington, DC

$10 \quad 20036$

11

$12 *$ Corresponding author; adelach@defenders.org

13

14 Current affiliations:

$15{ }^{4}$ Union of Concerned Scientists, Washington, DC

$16 \quad{ }^{5}$ Monterey Bay Aquarium, Monterey, CA

$17{ }^{6}$ Executive Office of Energy and Environmental Affairs, Commonwealth of Massachusetts, MA

$18 \quad{ }^{7}$ Wildlife Habitat Council, Silver Spring, MD 
Abstract

Despite widespread evidence of climate change as a threat to biodiversity, it is unclear whether government policies and agencies are adequately addressing this threat to species ${ }^{1-}$

${ }^{4}$. We evaluate species sensitivity, a component of climate change vulnerability, and whether climate change is discussed as a threat in planning for climate-related management action in official documents from 1973-2018 for all 459 US animals listed as endangered under the Endangered Species Act. We find that $99.8 \%$ of species are sensitive to one or more of eight sensitivity factors, but agencies consider climate change as a threat to only $64 \%$ of species and plan management actions for only $18 \%$ of species. Agencies are more likely to plan actions for species sensitive to more factors, but such planning has declined since 2016.

Results highlight the gap between climate change sensitivity and the attention from agencies charged with conserving endangered species.

Introduction

33 Climate change is a threat to ecosystems and biodiversity globally ${ }^{5,6}$, and has emerged as a driver of

34 observed and potential species decline and extinction ${ }^{7-9}$. Government laws and policies should play a

35 vital role in supporting climate change adaptation for imperiled species, yet imperiled species

36 protections have been critiqued as insufficient in Australia ${ }^{10,11}$, Canada ${ }^{12}$, and Europe ${ }^{13}$. Funding

37 shortfalls for environmental programs mean that governments may not be adequately addressing

38 baseline threats to species, let alone more complex emerging threats from climate change ${ }^{14,15}$.

39 Furthermore, the politicization of climate change in many countries, including the US, has led to

40 different levels of concern and action on the topic among political parties ${ }^{16,17}$. Understanding

41 whether and to what extent government authorities are supporting climate change adaptation, 
especially for imperiled species, is critical for improving tools and processes to reduce climate change impacts on biodiversity ${ }^{18,19}$.

The primary law directing the conservation of imperiled species in the US is the Endangered on the basis of five threat factors: 1) habitat destruction and degradation, 2) overutilization, 3) same year as the formation of the Intergovernmental Panel on Climate Change and four years before

53 the first detailed discussion the consequences of climate change for biological diversity in the $\mathrm{US}^{22}$. threat that climate change poses to species and the need to manage for its impacts. The FWS first maritimus) as threatened. Later that year, discussion of climate change appeared in recovery plans for the Indiana bat (Myotis sodalis) and Hawaiian monk seal (Monachus schauinslandi) and in five-year

61 documents, see archived data). The only assessment of climate change in ESA documents to date (to

62 our knowledge) found that by the end of $2008,87 \%$ of species recovery plans still did not address

63 whether or not climate change was a threat ${ }^{18}$. The scientific community has identified climate change 64 as the "primary threat" to nearly $40 \%$ of ESA-listed animals and over $50 \%$ of ESA-listed plants in

65 the $\mathrm{US}^{14}$, and agency options for climate-related management action under the ESA have been 
66 available for over a decade ${ }^{23}$. Thus, it is vital to understand whether the lead agencies responsible for

67 endangered species conservation have improved the use of their authority to help species adapt to

68 the threat of climate change.

To determine if threats from climate change are being addressed by US agencies, we compared

70 the climate change sensitivity of species to agencies' discussion of climate change and plans for

71 managing climate change threats for the 459 ESA-listed endangered animals found within US lands

72 and waters. Because climate change sensitivity had not been systematically assessed for many of

73 these species, we developed a trait-based climate change sensitivity assessment ${ }^{24}$. This assessment is

74 a simplified version of existing tools (see Methods) and provides a preliminary evaluation of whether

75 and which species' life history and biological characteristics contribute to sensitivity to climate

76 change (see Table 1). We focused on sensitivity (and related traits sometimes characterized as

77 measures of adaptive capacity) because these, rather than exposure, are the elements of vulnerability

78 that management plans can address ${ }^{10}$. Furthermore, because of the small populations and range sizes

79 of many of the species we evaluated, available exposure tools may not accurately capture granular

80 scale and stochastic effects in a meaningful way ${ }^{25}$. Focusing on sensitivity greatly reduced the time

81 required to assess each species, allowing the assessment to be applicable to large groups of species,

82 such as the $>2,300$ US and foreign species listed under the ESA. Our assessment relies on

83 affirmative statements about relevant aspects of biology and life history; certain traits had to be

84 identified in the literature for a species to be determined sensitive, and a species was considered not

85 sensitive by default. Therefore, the assessment represents a conservative estimate of sensitivity and

86 likely underestimated the actual sensitivity for some poorly-studied species or those for which that

87 information was not described in publicly available sources.

88 After assessing species sensitivity, we determined whether climate change was described as a

89 threat for species by reviewing official ESA documents published by FWS and NMFS. All 
endangered species have listing determinations, and most have either critical habitat designations,

91 five-year reviews, recovery plans, or recovery outlines. We focused on the most recently published one or two of these types of documents to determine if climate change was described as a threat. We then determined whether these agencies planned management action to address climate change threats as part of species recovery by evaluating the same ESA documents (excluding species whose only ESA document was a listing decision, as these are not management-oriented). We tested if

96 species sensitivity was a significant predictor of whether species ESA documents contained

97 discussion of climate change as a threat and to what extent federal agencies planned to respond to

98 climate change impacts. Data and results of the study are available in a free, interactive web

99 application at https://defenders-cci.org/app/ESA_climate/.

\section{Results and Discussion}

We found that nearly all endangered animals are sensitive to climate change impacts. All but one

103 (Hawaiian goose [Branta sandivicensis]) of the 459 species $(99.8 \%$ ) are sensitive to at least one of the

104 eight sensitivity factors (Table 1 ), and three-fourths $(74 \%)$ are sensitive to three or more factors (Fig.

105 1a). However, agencies describe climate change threats in documents for only slightly more than half

106 of species we assessed (64\%; Fig. 1b) and plan management actions to address those threats for only

107 a small fraction of species (18\%; Fig. 1c). Logistic regression indicated that the number of sensitivity

108 factors is a strong predictor of whether ESA documents discussed management action

$109(\mathrm{~F}(1,419)=6.57, \beta=-0.31, \mathrm{p}<0.01$; Fig. 1a). Agencies are more likely to plan climate adaptation

110 management actions for species that are sensitive to more climate factors than for species that are

111 sensitive to fewer factors; for example, documents for species sensitive to one vs seven factors are

$11210 \%$ vs $41 \%$ likely to contain management actions. Likewise, species sensitivity is marginally related

113 to whether climate change is considered as a threat $(F(1,458)=0.33, \beta=0.15, p=0.07$; Fig. 1a). These 
114 results indicate some prioritization of species based on potential climate threat and sensitivity,

115 though this may be unintentional. However, overall, there is a significant gap between the sensitivity

116 of endangered animals to climate change and the attention that climate change receives from the

117 agencies charged with recovery of these species.

118 The prevalence of sensitivity factors varied considerably. The highest proportion of species

119 across taxa was sensitive to isolation (mean across taxa $=0.71$, all taxa $\geq 0.50$ ), whereas the lowest

120 proportion was sensitive to phenology (mean $=0.09$, all taxa $\leq 0.21$; Fig. 2 a). Hydrology and

121 chemistry showed the highest variation in sensitivity across taxa (mean $=0.60, \mathrm{sd}=0.25, \mathrm{cv}=0.95$;

122 mean $=0.25, \mathrm{sd}=0.22, \mathrm{cv}=0.89$, respectively); disturbance showed the least (mean $=0.61, \mathrm{sd}=0.11$,

$123 \mathrm{cv}=0.17$; Fig. 2a). Of the taxa assessed, mammals were sensitive to the fewest number of factors

124 (Fig. 2b). Amphibians, mollusks, and arthropods were sensitive to the greatest number of factors;

125 many of these species exhibit an aquatic life cycle phase and are thus subject to hydrological and

126 chemical sensitivities. Furthermore, mollusks and arthropods also commonly depend on obligate

127 species relationships, although reproductive host species are not known for some mollusks.

128 Agencies appear to be prioritizing at least some of these high-sensitivity taxa for climate change-

129 related management. Arthropods and reptiles had the greatest proportion of species for which

130 climate change was evaluated as a threat (80\% and 75\%, respectively) and management action was

131 described (29\% and 28\%, respectively), whereas mollusks had the least (50\% and 31\%, respectively;

132 Fig. 3a-b).

133 Agencies have increasingly considered climate change as a potential threat to species in ESA

134 documents over time, mirroring rising concern about climate change over the past few decades ${ }^{26}$.

135 However, they have not yet widely translated this concern into articulated management actions to

136 help species adapt to climate change. After the agencies first described climate change as an

137 influence on habitat loss (listing factor 1) in 2007, the proportion of species with climate change 
mentioned in their ESA documents rose and thereafter stabilized at around 87\% of species in 2015-

1392016 (Fig. 4a). In 2017-2018 however, this trend reversed, with declines in both the proportion of

140 species where climate change was listed as a threat, and in the absolute number of newly published

141 ESA-related documents for endangered animals. With regard to management planning, climate

142 change was first identified as a topic for future study for the Indiana bat (Myotis sodalis) and

143 Choctawhatchee beach mouse (Peromyscus polionotus allophrys) in 2007, and the first discussion of

144 management action occurred in a 2008 recovery plan for the stellar sea lion (Eumetopias jubatus; Fig.

$1454 \mathrm{~b})$. The proportion of species with planned climate change-related action each year generally

146 increased until peaking in 2014. Since then, discussion of action has steadily declined; of documents

147 published in 2017, one species' five-year review (Kaua’i cave amphipod [Spelaeorchestia koloana])

148 described a management response to climate change, and no 2018 documents mentioned actions to

149 address climate impacts. In summary, although the number of ESA documents mentioning climate

150 change has increased over time, most species' documents either describe climate change as a

151 potential problem without including any actions to specifically address the issue, or the documents

152 do not discuss climate change at all. Across time(2007-2018), the proportion of species with planned

153 climate change-related action has been low on average (mean=0.23, range $=0.03-0.39$; Fig. 4b),

154 indicating a shortfall in planning of on-the-ground management for climate change that to date

155 shows no sign of improving.

156 In short, across time and taxa, management agencies are inadequately assessing climate change

157 threats, or planning action to manage those threats, to imperiled species. In terms of baseline

158 assessment, this inadequacy affects species regardless of their climate sensitivity, as we found no

159 relationship between the number of sensitivity factors and the consideration of climate change as a

160 potential threat. Agencies may be inadvertently prioritizing species for management planning based

161 on their degree of sensitivity to climate factors, however we caution that the mere presence of 
162 management action in documents does not assure the adequacy of plans or, more importantly, the

163 enactment of those plans ${ }^{10}$. Even for species with planned actions, we observed substantial variation

164 in the content: several five-year reviews merely recommended updating recovery plans to include

165 climate change. More robust discussions for action entailed protecting refugia (e.g., Chinook salmon

166 [Oncorbynchus tshanytscha] and white abalone [Haliotis sorenseni] recovery plans) and diverse microsites

167 (e.g., Karner blue butterfly [Lycaeides melissa samuelis] five-year review), improving connectivity (e.g.,

168 jaguar [Panthera onca] recovery plan), establishing additional populations for redundancy in case of

169 stochastic climate events (e.g., Sonoran pronghorn [Antilocapra americana sonoriensis] recovery plan),

170 reducing non-climate-related threats (e.g., water allocations in spikedace [Meda fulgida] five-year

171 review), and designating critical habitat in areas likely to persist or become important areas in the

172 future (e.g., tidewater goby [Eucyclogobius newberryi] and Bartram's scrub-hairstreak butterfly [Strymon

173 acis bartrami] critical habitat designations). Our results offer insights for how agencies, including

174 different management jurisdictions (see Supplemental Information), might prioritize the types of

175 climate change adaptation options to target susceptible taxa and sensitivity factors.

176 Three main issues may explain why the relevant US agencies have yet to address climate change

177 threats as part of their imperiled species conservation programs. First, the politicization of climate

178 change has caused its prioritization to shift every 4 or 8 years with changes in Presidential

179 administration. In 2017, the Trump administration revoked many policies and commitments on

180 climate change established by the Obama Administration, such as Executive Order 13653 on

181 adaptation ${ }^{27}$ and the Paris Global Climate Agreement. ${ }^{27,28}$. This has disrupted progress on both

182 mitigation and adaptation nationally and internationally ${ }^{3}$. Imperiled species conservation in the face

183 of climate change urgently requires the return of a bipartisan and durable commitment to both

184 mitigation of and adaptation to climate change. For example, legislative bodies, such as the US 
185 Congress and central governments in other countries, could integrate climate change adaptation and

186 mitigation into law rather than leaving these important processes to more labile policies.

187 Second, the infrequent and inconsistent inclusion of climate change in ESA species conservation

188 may be a consequence of chronic underfunding and imbalanced funding of species recovery. In

189 fiscal year 2012, $62 \%$ of species recovery funding was spent on the conservation of $10 \%$ of US listed

190 species, resulting in as little as $\$ 60$ for some species (e.g., Cumberland bean mussel [Villosa trabalis]

191 whose ESA documents did not mention climate change $)^{14,29,30}$. Another analysis of yearly

192 appropriations from 1980-2014 found that <25\% of required recovery funding has been allocated

193 annually ${ }^{31}$. Increased funding to the agencies responsible for species recovery, paired with a more

194 informed allocation of resources, could help redress this problem ${ }^{15,31}$.

195 Finally, climate change itself is a formidable conservation challenge that agencies generally lack

196 the logistical tools and capacity to address. The broad spatial and temporal scales and uncertainty of

197 specific threats mean that agencies should pair conceptual models with mechanistic approaches to

198 identify stressors that materialize as species threats ${ }^{2,32}$. Agencies would benefit from embracing the

199 frameworks designed to enable systematic planning, implementing, and monitoring of complex

200 conservation challenge, and integrate climate change with other threats ${ }^{33,34}$. Additionally, agencies

201 should proactively seek and embrace innovative tools that enable efficient management of the

$2022,300+$ imperiled species listed on the ESA. The assessment used in this study is one such example,

203 offering a time-efficient method for preliminary evaluations of species sensitivity to climate change.

204 Our study reveals that US government agencies have yet to adequately evaluate climate change

205 threats to endangered animals listed under the ESA and plan commensurate action. The consistency

206 between our US results and recent findings from Australia ${ }^{10,11}$ suggest it is possible that many

207 countries are similarly failing to protect imperiled species from climate change impacts. Climate

208 change poses an ongoing and accelerating threat to many, if not most, imperiled species, and 
recovery will be unattainable unless a feasible process is in place to account for and ameliorate its

210 impacts.

\section{Methods}

213 We compared the climate change sensitivity of species to agency evaluation and management

214 planning of climate change threats for ESA-listed endangered animals in the US. First, since

215 systematic data did not exist for the climate change impacts on endangered species, we developed

216 and conducted a trait-based, rapid assessment for evaluating climate change sensitivity. We focused

217 the assessment on one element of species vulnerability: a species' potential "sensitivity" to the effects

218 of climate change. Sensitivity "refers to innate characteristics of a species or system and considers

219 tolerance to changes in such things as temperature, precipitation, fire regimes, or other key

220 processes" ${ }^{35}$. We created and answered eight yes-or-no questions based on whether the species'

221 habitat, ecology, physiology, or life cycle might be affected by changes in climate (Table 1). In doing

222 so, we employed a biological approach to assessing sensitivity that considered the ecological impact

223 to the species from the primary manifestations of climate change, including indirect impacts from

224 effects on interacting species ${ }^{24}$. We derived the questions, or sensitivity factors, from factors listed in

225 existing vulnerability assessment protocols, particularly the NatureServe Climate Change

226 Vulnerability Index ${ }^{36}$ and US Forest Service's System for Assessing Vulnerability of Species ${ }^{37}$.

227 Though not exhaustive, our questions covered the main categories of species sensitivity (or

228 sometimes categorized under adaptive capacity) in these and other assessment frameworks ${ }^{38}$. We

229 were thus able to assess many of the elements of vulnerability that can be addressed via management

230 planning, while also completing most species in 30-60 minutes. This assessment could be useful to

231 agencies for evaluating large numbers of species while still capturing the most critical elements of

232 potential species sensitivity. 
We assessed the climate change sensitivity of all animal species listed as endangered under the

234 ESA (as of December 31, 2018) that are found in US states, territories, and surrounding waters

235 ( $n=459 ;$ see http://www.fws.gov/endangered), with the exception of those deemed likely to be

236 extinct by agencies or which have not been observed for $20+$ years and are likely extinct in the wild.

237 We answered the assessment questions using freely-accessible species information from species

238 listing decisions and other publicly available information published by agencies and conservation

239 organizations about the species and its threats. We predominantly referenced the FWS'

240 Environmental Conservation Online System (ECOS; https://ecos.fws.gov/ecp), NMFS'

241 Endangered Species Conservation Directory (https://www.f1sheries.noaa.gov/species-

242 directory/threatened-endangered), and the NatureServe Explorer (http://explorer.natureserve.org).

243 Using publicly available information enables the assessment to be used by the public or government,

244 the latter of which requires decision data to be publicly visible ${ }^{39,40}$.

245 Consistency in measuring species sensitivity both within and between assessment tools is a

246 recognized and ongoing challenge $e^{41,42}$. We took steps to ensure that sensitivity results were consistent

247 within and between species in our assessment. Each species was assessed by at least two and as

248 many as seven reviewers; species were initially reviewed by at least one of six reviewers (AC, KE,

249 RK, SM, KT and LV) and were finally crosschecking by an expert reviewer (AD). All reviewers went

250 through extensive training to ensure consistency in the application of the methodology (Table 1),

251 including assessing and comparing the same species to validate and align the approach.

252 We also evaluated the extent to which FWS' and NMFS' ESA documents discussed climate

253 change as a threat to species and included planned recovery actions to address climate change

254 impacts. First, for all endangered animals, we recorded whether climate change was considered as a

255 potential threat in each species' publicly available ESA documents (listing decisions, recovery plans

256 and outlines, critical habitat designations, and five-year reviews). We focused on the most recently 
257 published agency documents, which should reflect cumulative knowledge about the species. Then,

258 for all endangered animals except those with only listing decisions, which are not management-

259 oriented and thus not appropriate for evaluating management planning ( $n=420$; excluded species

$260 \mathrm{n}=39)$, we recorded what level of management action was discussed to address climate change in

261 species recovery. We recorded the level of discussion as: "Action," indicating that the documents

262 articulated specific actions in response to climate change impacts; "Further study," indicating that

263 the agency acknowledged they require additional information before an action plan could be

264 developed; "No threat, no action needed," indicating that the documents discussed climate change

265 and decided that climate change is unlikely to impede species recovery; and "No discussion,"

266 indicating that climate change was not mentioned.

267 We examined patterns in sensitivity and climate change discussion by time, taxa, agency and 268 regional jurisdiction (see Supplemental Information for latter two). We tested the relationships

269 between the number of sensitivity factors and whether documents discussed climate change as a

270 potential threat (yes/no) or discussed management action (by reclassifying discussion categories to

271 create a binary variable of no action/action) using logistic regression run with the 'stats' package in $\mathrm{R}$

272 v.3.5.0.

274 Acknowledgements

275 We thank Natalie Dubois and Noah Matson for valuable input and Bob Dreher, Michael Evans,

276 Meg Evansen, Mae Lacey, Sasha Pastel, Shayna Steingard for feedback on the manuscript. Financial

277 support for data collection was provided by University of Maryland and the Stanback Internship

278 Program of Duke University.

\section{Author Contributions}


A.D. and A.C. designed the study; A.D., A.C., K.E., R.K., S.M., K.T., and L.V. collected data; A.D. and J.R.B.M. analyzed data and wrote the manuscript; A.D., J.W.M., M.S., and J.R.B.M. interpreted results; J.W.M. built the web app; all authors provided critical feedback on the manuscript.

\section{Data Availability}

Data is archived on Open Science Framework and available at https://osf.io/rOuca. A free,

287 interactive web application containing data and results from this study is available at https://

288 defenders-cci.org/app/ESA_climate/.

\section{Competing Interests}

291 The authors declare no competing financial interests.

\section{Additional information}

294 Supplementary information is available in the online version of the paper.

\section{References}

297 1. McClanahan, T. R. et al. Conservation action in a changing climate. Conserv. Lett. 7, i-ii (2014).

298 2. Mawdsley, J. R., O’Malley, R. \& Ojima, D. S. A review of climate-change adaptation strategies

299 for wildlife management and biodiversity conservation. Conserv. Biol. 23, 1080-1089 (2009).

$3003 . \quad$ Bierbaum, R. et al. A comprehensive review of climate adaptation in the United States: more

301 than before, but less than needed. Mitig. Adapt. Strateg. Glob. Chang. 18, 361-406 (2013).

302 4. Wilcove, D. S., Rothstein, D., Dubow, J., Phillips, A. \& Losos, E. Quantifying threats to 303 imperiled species in the United States. Bioscience 48, 607-615 (1998).

304 5. Lipton, D. et al. Ecosystems, Ecosystem Services, and Biodiversity. in Impacts, Risks, and 
6. IPCC. Climate Change 2014: Synthesis Report. Congribution of Working Groups I, II and III to the Fifth Assessment Report of the Intergovernmental Panel on Climate Change. (IPCC, 2014).

7. Pounds, J. et al. Widespread amphibian extinctions from epidemic disease driven by global warming. Nature 439, 161-167 (2006).

312 8. Urban, M. Accelerating extinction risk from climate change. Science. 348, 571-573 (2015).

313 9. Díaz, S. et al. Summary for policymakers of the global assessment report on biodiversity and ecosystem services 314 of the Intergovernmental Science-Policy Platform on Biodiversity and Ecosystem Services. (2019).

315 10. Butt, N. \& Gallagher, R. Using species traits to guide conservation actions under climate change. Clim. Chang. 151, 317-332 (2018).

317 11. Hoeppner, J. M. \& Hughes, L. Climate readiness of recovery plans for threatened. Conserv. Biol. 33, 534-542 (2019).

319 12. Scott, D. \& Lemieux, C. Climate change and protected area policy and planning in Canada. Forestry 81, 696-703 (2005).

321 13. Araújo, M., Alagador, D., Cabeza, M., Nogués-Bravo, D. \& Thuiller, W. Climate change

14. Evans, D. M. et al. Species recovery in the United States: increasing the effectiveness of the 
American public's views of global warming, 2001-2010. Sociol. Q. 52, 155-194 (2011).

330 17. McCright, A. M., Dunlap, R. E. \& Marquart-Pyatt, S. T. Political ideology and views about climate change in the European Union. Env. Polit. (2015).

18. Povilitis, A. \& Suckling, K. Addressing climate change threats to endangered species in US recovery plans. Conserv. Biol. 24, 372-376 (2010).

19. Bernazzani, P., Bradley, B. A. \& Opperman, J. J. Integrating climate change into Habitat Conservation Plans under the US Endangered Species Act. Environ. Manage. 49, 1103-1114 (2012).

338 20. US Congress. The Endangered Species Act of 1973. (1973).

339 21. US Congress. Endangered Species Act Amendments of 1988. (1988).

340 22. Peters, R. \& Lovejoy, T. Global Warming and Biological Diversity. (Yale University Press, 1992).

341 23. Ruhl, J. Climate change and the Endangered Species Act: building bridges to the no-analog 342 future. Environ. Law Policy Annu. Rev. 39, 10735-10745 (2009).

343 24. Pacifici, M. et al. Assessing species vulnerability to climate change. Nat. Clim. Chang. 5, 215225 (2015).

345 25. Case, M. J., Lawler, J. J. \& Tomasevic, J. A. Relative sensitivity to climate change of species in 346 northwestern North America. 187, 127-133 (2015).

347 26. Gustafson, A., Leiserowitz, A. \& Maibach, E. Americans are Increasingly 'Alarmed' About $348 \quad$ Global Warming. Climate Note (2019). Available at: http://climatecommunication.yale.edu/publications/americans-are-increasingly-alarmed-

350 about-global-warming/.

351 27. President of the United States. Executive Order 13783. Promoting Energy Independence and 352 Economic Growth. (2017). 
353

354

355

356

357

358

359

360

361

362

363

364

365

366

367

368

369

370

371

372

373

374

375

376

28. Shear, M. Trump will withdraw US from Paris Climate Agreement. The New York Times (2017).

29. US Fish and Wildlife Service. Federal and State Endangered and Threatened Species Expenditures. (2012).

30. Platt, J. How much did the US spend on the Endangered Species Act in 2012? Scientific American (2013).

31. Gerber, L. R. Conservation triage or injurious neglect in endangered species recovery. Proc. Natl. Acad. Sci. 113, 3563-3566 (2016).

32. Heller, N. \& Zavaleta, E. Biodiversity management in the face of climate change: a review of 22 years of recommendations. Biol. Conserv. 142, 14-32 (2009).

33. Geyer, J. et al. Classification of climate-change-induced stresses on biological diversity. Conserv. Biol. 25, 708-715 (2011).

34. Schwartz, M. W. et al. Decision support frameworks and tools for conservation. Conserv. Lett. 11, e12385 (2018)

35. Glick, P., Stein, B. A. \& Edelson, N. A. Scanning the Conservation Horizon. (National Wildlife Federation, 2011).

36. Young, B. E., Dubois, N. S. \& Rowland, E. L. Using the climate change vulnerability index to inform adaptation planning: Lessons, innovations, and next steps. Wildl. Soc. Bull. 39, 174-181 (2015).

37. Bagne, K. E., Friggens, M. M. \& Finch, D. M. A System for Assessing V ulnerability of Species (SAVS) to Climate Change. (2011).

38. Foden, W. B. et al. Climate change vulnerability assessment of species. WIREs Clim. Chang. 10, $1-36(2018)$.

39. US Fish and Wildlife Service. US Fish and Wildlife Service Information Quality Guidelines and Peer 
Review. (2012).

378 40. National Oceanic and Atmospheric Administration. NAO 202-735D: Scientific Integrity. (2011).

379 41. Lankford, A. J., Svancara, L. K., Lawler, J. J. \& Vierling, K. Comparison of climate change

380 vulnerability assessments for wildlife. Wildl. Soc. Bull. 38, 386-394 (2014).

381 42. Wheatley, C. J. et al. Climate change vulnerability for species - Assessing the assessments. 
a

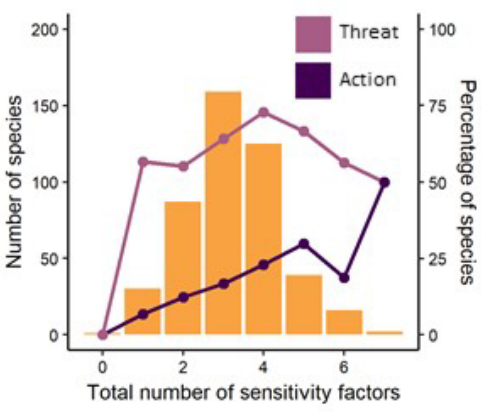

b

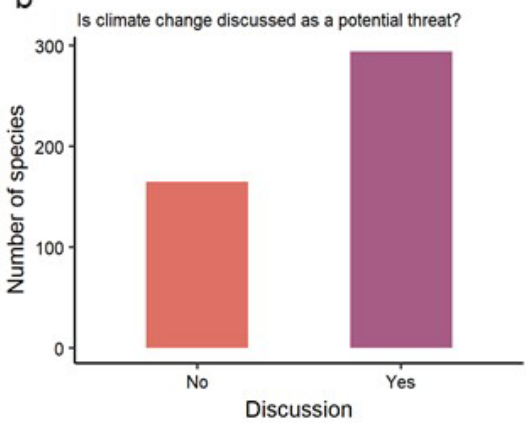

c

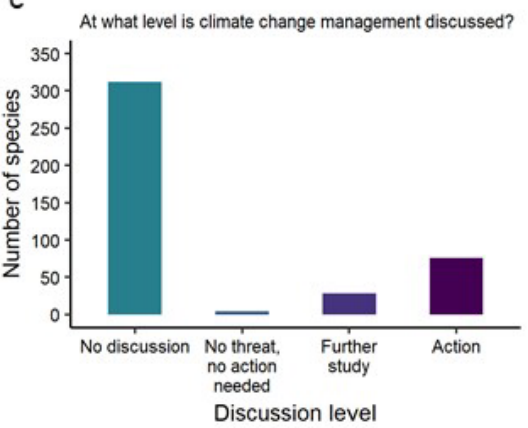

Figure 1. Despite sensitivity to one or more climate factors (a), US endangered animals are

not often assessed for whether climate change is a potential threat (b) and most do not

387 that are sensitive to more climate factors are more likely to receive management action planning

388 (dark purple line; $\mathrm{p}<0.05$ ) than species sensitive to fewer factors, and are marginally more likely to

389 receive evaluation of climate change as a threat (light pink line; $\mathrm{p}=0.07$ ). All endangered animals

390 except one (Hawaiian goose [Branta sandicensis]) are sensitive to one or more of eight climate factors

391 (see Table 1 for description of factors). The two most sensitive species (seven factors) were a fish,

392 the Clear Creek gambusia (Gambusia heterochir), and a mollusk, the shinyrayed pocketbook (I ampsilis

393 subangulata). Bars represent the number of species; lines represent the proportion of species within

394 each number of sensitivity factors. Analysis in (a) and (b) contain all endangered animals on the

395 ESA ( $\mathrm{n}=459)$; analysis in (c) excludes species for which only listing decisions exist (excluded $n=39$;

396 included $n=420$; see text for details). Colors correspond to Fig. 2, 3, and 4. 
a
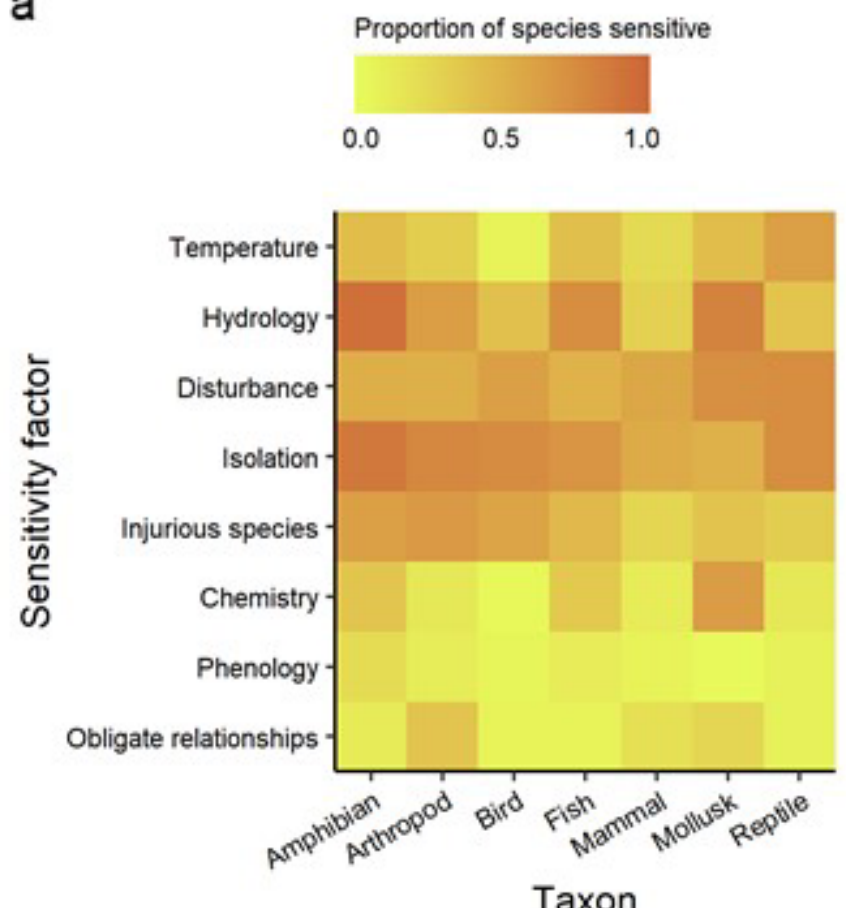

b

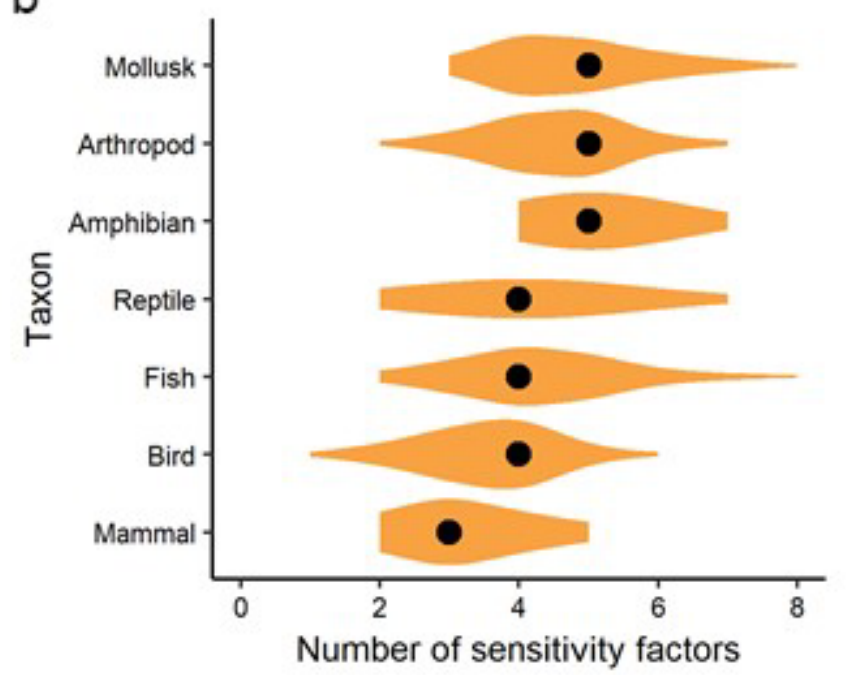

398 Figure 2. Taxa differ in sensitivity to the (a) type and (b) total number of climate factors.

399 Analysis includes all 459 endangered species listed on the Endangered Species Act. See Table 1 for

400 descriptions of factors, Supplementary Table 1 for the number of species in each taxa, and

401 Supplementary Figure S1 for taxa sensitivity by factor across management agency and region. 
Is climate change discussed as a potential threat?

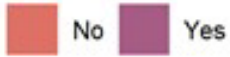

a

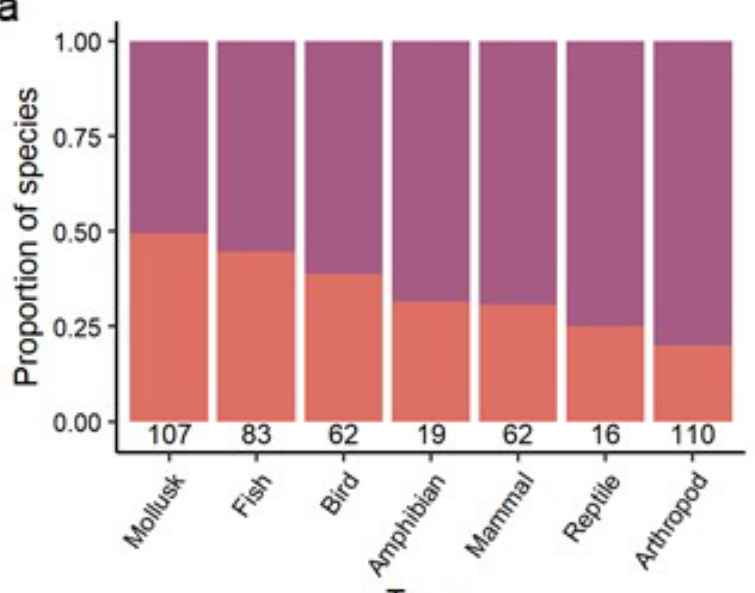

Taxon
At what level is climate change management discussed?

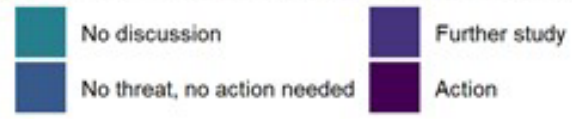

b

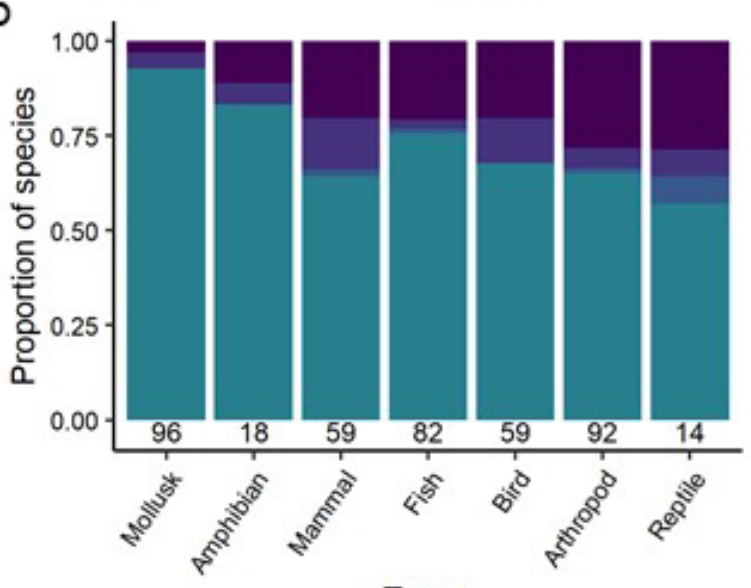

Taxon

403 Figure 3. Taxonomic differences occur in whether (a) and how (b) climate change is

404 discussed in official management documents for endangered animals. Analysis in a contains

405 all 459 endangered animals listed on the Endangered Species Act; analysis in $\mathbf{b}$ excludes species for

406 which only listing decisions exist (excluded $n=39$; included $n=420$; see text for details). The number

407 of species in each group is shown above the $\mathrm{x}$-axis. 
a
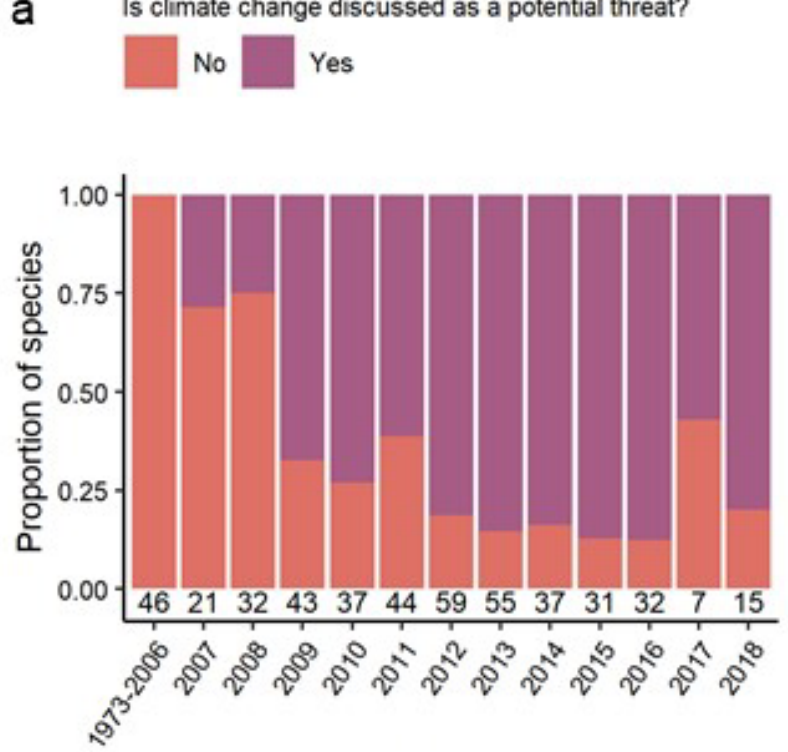

Date
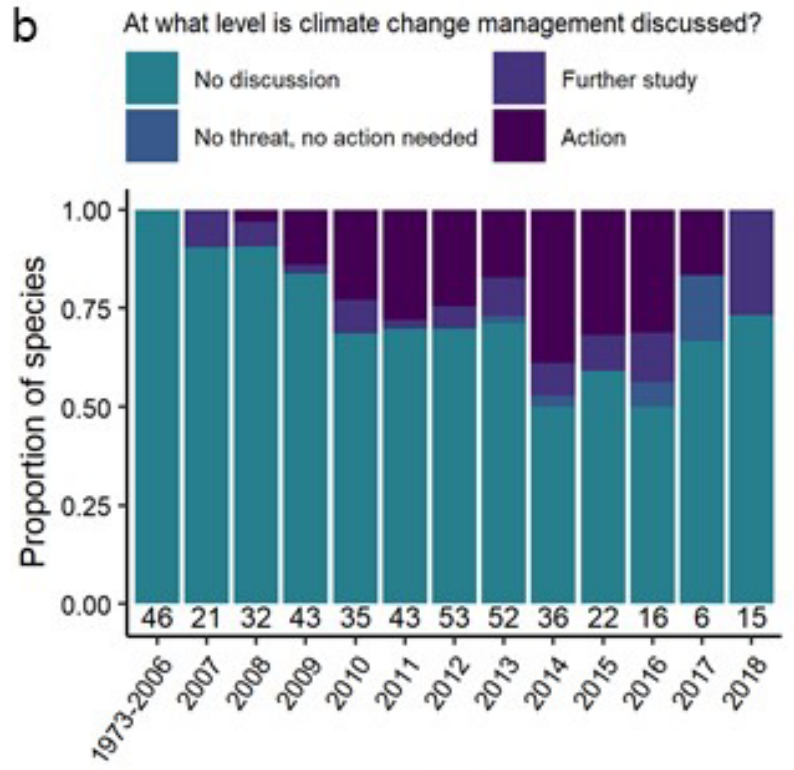

Date

409 Figure 4. Over time US agencies have included discussions about climate change in official

410 documents for more endangered animals, but (a) baseline assessments of climate change as

411 a threat have increased at a substantially faster rate than (b) planning of management

412 action. Analysis in a contains all 459 endangered animals listed on the Endangered Species Act;

413 analysis in $\mathbf{b}$ excludes species for which only listing decisions exist (excluded $n=39$; included $n=420$;

414 see text for details). The number of species in each group is shown above the $\mathrm{x}$-axis. 
415 Table 1. Questions in the rapid sensitivity assessment related to eight climate change sensitivity

416 factors.

\begin{tabular}{|c|c|}
\hline Factor & Question and description \\
\hline Temperature & $\begin{array}{l}\text { Does the species have specialized thermal tolerance or depend on habitat with an } \\
\text { important temperature threshold? Species were considered temperature sensitive if } \\
\text { available information indicated the species has or depends on habitats with obligate } \\
\text { or preferential temperature thresholds (e.g., sea ice). }\end{array}$ \\
\hline Hydrology & $\begin{array}{l}\text { Is the species dependent on habitat with a specialized hydrology? Species were } \\
\text { considered sensitive if available information indicated they require narrow ranges of } \\
\text { water depths, flow rates, timing, or seasonality (e.g., vernal pools or intermittent } \\
\text { streams). }\end{array}$ \\
\hline Disturbance & $\begin{array}{l}\text { Is the species or its habitat sensitive to or dependent on a specific disturbance } \\
\text { regime? This includes species in fire-adapted systems, species that rely on certain } \\
\text { flood regimes, and species impaired by disturbance, such as old-growth forest } \\
\text { obligates and species sensitive to excessive flooding. }\end{array}$ \\
\hline Isolation & $\begin{array}{l}\text { Is the species or its habitat geographically restricted or does it face intrinsic or } \\
\text { extrinsic barriers to shifting its range to maintain its climate space? While many } \\
\text { endangered species are found in small, isolated populations, we scored species in this } \\
\text { category if available information indicated they are confined to mountains, islands, } \\
\text { or headwaters; are narrowly endemic to spatially discrete habitats, like caves, springs } \\
\text { or rare soil types; or if species movement to other suitable habitat is limited by } \\
\text { habitat loss, development, dams, or other anthropogenic pressures. }\end{array}$ \\
\hline
\end{tabular}




\begin{tabular}{|l|l|}
\hline Injurious & $\begin{array}{l}\text { Is the species or its habitat threatened by an invasive species, pest and/or disease } \\
\text { organism that might benefit from climate change? We did not consider the species } \\
\text { in question sensitive where the injurious species is ubiquitous or human-oriented } \\
\text { (e.g., cats, rats, livestock). }\end{array}$ \\
\hline Chemistry & $\begin{array}{l}\text { Is the species sensitive to changes in chemical concentration, such as atmospheric } \\
\text { CO, water pH, or dissolved oxygen? }\end{array}$ \\
\hline Phenology & $\begin{array}{l}\text { Does the species rely on specific triggers for life cycle events, such as breeding, } \\
\text { migration, or color change, that are likely to become out of sync with seasonal } \\
\text { changes in resource availability or environmental conditions (i.e., phenologic } \\
\text { mismatch)? }\end{array}$ \\
\hline Obligate & $\begin{array}{l}\text { Is the species dependent on one or a few species such as a host, dominant food } \\
\text { source, with limited alternatives if the required species declines due to climate } \\
\text { shange? We did not consider the species sensitive if it requires a host but can } \\
\text { succeed in association with four or more species. }\end{array}$ \\
\hline
\end{tabular}

